\title{
The Association Between Adherence to Insulin Therapy and Health Care Costs for Adults with Type 2 Diabetes: Evidence from a U.S. Retrospective Claims Database
}

\author{
Elizabeth L. Eby, MPH; Sanjay Bajpai, PhD; Douglas E. Faries, PhD; \\ Virginia S. Haynes, PhD; and Maureen J. Lage, PhD
}

\begin{abstract}
BACKGROUND: Research has shown that many patients with type 2

diabetes (T2D) are not adherent to their medication regimen.

OBJECTIVE: To examine the association between adherence to insulin therapy and all-cause health care costs for patients with T2D.

METHODS: This study used the IQVIA PharMetrics Plus Linkable to Ambulatory Electronic Medical Record data from January 1, 2012, through September 30, 2017. Patients were included if they were identified with T2D and initiated therapy on basal insulin (BAS) or basal-bolus (BAS-BOL) combination at any time from January 1, 2013, through 0ctober 1, 2016. Patients aged $<18$ years, who used an insulin pump, identified as pregnant, or did not have continuous insurance coverage from 1 year before initiation on insulin therapy through 1 year after initiation were excluded. Descriptive statistics compared patient characteristics and costs (in U.S. 2017 dollars) between patients who were adherent or nonadherent to their insulin therapy in the 1-year postperiod, where adherence was defined as having proportion of days covered (PDC) of at least $80 \%$. In addition, generalized linear models were used to compare costs between adherent and nonadherent patients, while controlling for patient characteristics, previous general health and comorbidities, resource utilization, medication use and type of insulin.
\end{abstract}

RESULTS: 13,296 patients were included in the BAS cohort (5,502 adherent; 7,794 nonadherent) and 10,069 in the BAS-BOL cohort (2,006 adherent; 8,063 nonadherent). Adherent patients had significantly lower all-cause total unadjusted costs following initiation on BAS $(\$ 29,322$ vs. $\$ 31,888$, $P=0.0134$ ) and BAS-BOL combination ( $\$ 36,229$ vs. $\$ 40,147, P=0.0078$ ). Drug costs comprised $39.5 \%-45.4 \%$ of costs among adherent patients and $23.0 \%-25.9 \%$ of costs among nonadherent patients. Multivariable analyses revealed that adherent patients had significantly lower adjusted all-cause total costs than nonadherent patients in the BAS cohort $(\$ 30,127$ vs. $\$ 37,049,95 \% \mathrm{Cl}$ for difference $-\$ 8,460$ to $-\$ 5,384$ ) and the BAS-BOL cohort $(\$ 36,603$ vs. $\$ 44,702,95 \%$ Cl for difference $-\$ 9,129$ to $-\$ 6,980)$.

CONCLUSIONS: In patients with T2D who initiated BAS or BAS-BOL combination therapy, adherence was associated with significantly lower all-cause total health care costs, despite significantly higher drug costs. These results illustrate the potential economic benefits associated with adherence to insulin therapy.

J Manag Care Spec Pharm. 2020;26(9):1081-89

Copyright @ 2020, Academy of Managed Care Pharmacy. All rights reserved.

\section{What is already known about this subject}

Most patients with type 2 diabetes will eventually require insulin therapy.

Adherence to insulin therapy has been shown to be associated with better patient outcomes, including improved glycemic control, reduced resource use, and decreased mortality.

Previous research, which has focused on the relationship between adherence and health care costs, has found mixed results, although most studies found that increased adherence was associated with lower total costs.

\section{What this study adds}

This study expands knowledge of the association between adherence to insulin therapy and health care costs by focusing on 2 common insulin regimens: basal insulin and basal-bolus combination therapy.

This study provides updated information on the costs associated with adherence to insulin therapy.

$\mathrm{M}$ ost patients with type 2 diabetes (T2D) will eventually require insulin therapy. ${ }^{1}$ In general, adherence to insulin therapy has been shown to be associated with better patient outcomes, including improved glycemic control, ${ }^{2}$ reduced resource use, ${ }^{3}$ and decreased mortality. ${ }^{4}$ However, in a multinational survey of individuals diagnosed with diabetes and treated with insulin, one third (33.2\%) of the patients reported that they had been nonadherent to their insulin therapy for at least 1 day during the previous month. ${ }^{5}$ More recently, research that captured adherence using a Bluetoothenabled pen cap found that $100 \%$ of patients prescribed multiple daily injections had at least 1 deviation from their insulin prescription over a 1-month time period and that rates of nonadherence ranged from $24 \%$ for patients treated with bolus insulin to $36 \%$ for patients treated with basal insulin. ${ }^{6}$ Consistent with the nonadherence found by patient self-report and technology-aided measures, nearly three quarters (72.5\%) of physicians surveyed reported that their patients do not take insulin as prescribed. ${ }^{5}$ 


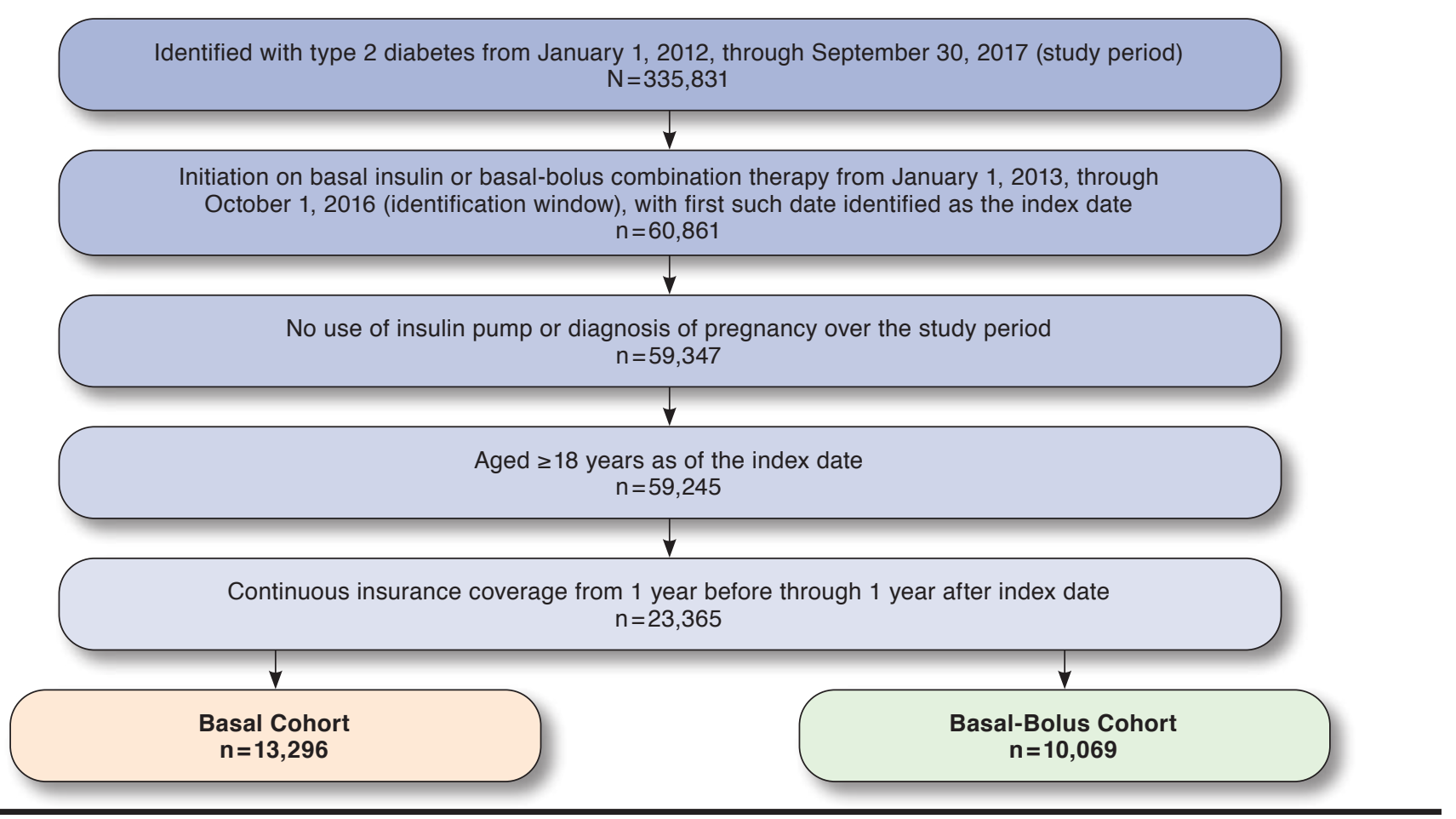

A review of the literature on medication adherence and health care costs among patients with T2D found that, in general, improved adherence to insulin was associated with reduced health care costs. ${ }^{7}$ The previous literature focused on basal insulin, ${ }^{3}$ the method of insulin delivery, ${ }^{8-10}$ or comparisons between U-500 and U-100 insulin. ${ }^{11}$ However, according to guidelines from the American Diabetes Association, many T2D patients require fast-acting (bolus) insulin at mealtimes, in addition to taking basal insulin, to achieve target hemoglobin Alc. ${ }^{12}$

The goal of this study was to further the literature by examining the concurrent association between all-cause health care costs and adherence to either basal insulin (BAS) or basal and bolus combination (BAS-BOL) therapy. As such, this study provides updated information on the costs associated with adherence to insulin therapy. Additionally, it compared the observed unadjusted and adjusted costs of 2 common insulin regimens (BAS and BAS-BOL).

\section{Methods}

Study data came from the IQVIA PharMetrics Plus Linkable to Ambulatory Electronic Medical Record data. The combined data houses information on patient demographics, clinical encounters, laboratory test results, observational information such as body mass index and blood pressure, and insurance claims (inpatient and outpatient), including claims for prescription medications. All of the data used in this study were fully deidentified, HIPAA compliant, and collected between January 1, 2012, and September 30, 2017. As a retrospective, deidentified database, approval by an institutional review board was not required.

\section{Patient Sample}

Patients were included in the study if they were identified as having T2D based on a previously published algorithm, ${ }^{13}$ over the time period from January 1, 2013, through October 1, 2016 (the identification window). In addition, all patients were required to have filled their initial prescription for BAS or BASBOL during the identification window, with the first such date identified as the index date, and to have continuous insurance coverage from 1 year before the index date (preperiod) through 1 year after the index date (postperiod).

Patients were excluded from the BAS and BAS-BOL cohorts if at any time from the start of the preperiod through the end of the postperiod they were identified as pregnant, diagnosed with gestational diabetes, or had a record of insulin pump use. Patients were also excluded if they were aged $<18$ years as of the index date. Patients in the BAS cohort were also excluded if they used any insulin during the preperiod. The final sample consisted of 13,296 individuals in the BAS cohort and 10,069 
in the BAS-BOL cohort. Figure 1 illustrates how each of the inclusion and exclusion criteria affected sample size.

\section{Outcomes}

This study focused on the association between patient adherence to insulin therapy and costs. Adherence was proxied by the proportion of days covered (PDC). PDC was chosen as the measure of adherence, since it is used by the Pharmacy Quality Alliance and the Centers for Medicare \& Medicaid Services when examining treatment of patients with chronic conditions such as diabetes. ${ }^{14,15}$ In general, PDC was constructed with a numerator of the number of unique days during the postperiod that an individual had a supply of the intent-totreat insulin (BAS or BAS-BOL), while only counting once if multiple prescriptions for the drug of interest is prescribed with overlapping days supply, and a denominator of the length of the postperiod (365 days). ${ }^{16}$ However, although the days supply field for insulin use is typically recorded as 30 days, ${ }^{17}$ insulin use depends on a variety of factors such as package size, carbohydrate intake, physical activity, body mass, illness, and insulin resistance. ${ }^{18}$ To account for this discrepancy, the days supply field was adjusted using a previously published algorithm. Specifically, for each insulin drug and delivery unique combination, an adjustment factor was calculated as the median time between insulin claims divided by the median pharmacy days supply (30 days). ${ }^{17}$ Consistent with a wide range of previous research, a threshold of $80 \%$ was used to classify a patient as adherent. ${ }^{19}$ Costs were defined as the contracted or accepted reimbursable amount for covered medical services or supplies that the health plan agreed to pay to service providers and were adjusted to U.S. 2017 dollars using the medical component of the Consumer Price Index. ${ }^{20}$

\section{Analyses}

This study examined the unadjusted differences in patient characteristics based on adherence status using t-statistics for continuous variables and chi-square statistics for categorical variables. The primary analyses examined the relationship between adherence and all-cause or diabetes-related costs, where diabetes-related costs were defined as all costs with an accompanying diagnosis of diabetes or receipt of a glucose-lowering agent (GLA). In addition, the analyses looked at several subcomponents of total health care costs. These subcomponents included drug costs, outpatient costs, and acute care (i.e., hospital and emergency room [ER]) costs. Generalized linear models with gamma distribution and log link were used to estimate all total costs, drug costs, and outpatient costs. ${ }^{21}$ Two-part models were used to estimate acute care costs. ${ }^{22}$

Separate models estimated costs for adherent and nonadherent patients. For each patient, 2 estimates of costs were computed: one assuming the patient was adherent (using the first model) and another assuming that the patient was nonadherent (using the second model). The difference in costs if adherent versus nonadherent were computed for each patient and averaged across the entire sample. Confidence intervals (CI) for costs differences were calculated using nonparametric bootstrap (random sampling with replacement) with 2,000 iterations to create a distribution where the 2.5th and 97.5 th percentiles were the $95 \%$ CI lower and upper limits, respectively.

All analyses controlled for patient characteristics (age, sex, region of residence, and body mass index); preperiod general health (Charlson Comorbidity Index $[\mathrm{CCI}]^{23}$ and Diabetes Complications and Severity Index [DCSI] ${ }^{24}$ ); certain preperiod comorbidities not captured in the CCI or DCSI (anxiety, depression, hyperlipidemia, and hypoglycemia); preperiod resource utilization (visit to cardiologist, endocrinologist, ophthalmologist, nephrologist, hospital, or ER, as well as the number of Alc laboratory test results ordered and the number of outpatient visits); preperiod use of GLAs (the number of oral medications prescribed and the receipt of a noninsulin injectable); and initial insulin type prescribed in the first month of the postperiod (analog or regular insulin).

All analyses were conducted using SAS, version 9.4 (SAS Institute, Cary, NC). A $P$ value $<0.05$ was considered, a priori, to be statistically significant.

\section{Results}

Table 1 presents the descriptive statistics for the 13,296 individuals in the BAS cohort and the 10,069 individuals in the BAS-BOL cohort, based on adherence categorization. In the BAS cohort, $41.4 \%$ of patients were classified as adherent (PDC $\geq 80 \%$ ), while $19.9 \%$ of patients in the BAS-BOL cohort were classified as adherent. Results revealed that, in both cohorts, there were relatively small, but statistically significant, differences between adherent and nonadherent patients. For example, adherent patients were statistically significantly older, had a statistically significantly higher proportion of males, and had a statistically significantly higher body mass index.

In addition, there were indications from both cohorts that adherent patients were in better general health compared with nonadherent patients. Specifically, in both cohorts, adherent patients had statistically significantly lower DCSI scores and had a statistically significantly lower proportion of comorbid anxiety, visits to a cardiologist, an ER visit, or a hospitalization in the preperiod. However, compared with nonadherent individuals, in the preperiod adherent patients in both cohorts had a statistically significantly higher proportion of comorbid hyperlipidemia, use of a noninsulin injectable, and laboratory orders for Alc tests. Adherent patients also were prescribed statistically significantly more distinct classes of oral antidiabetic medicines and GLAs overall in the preperiod, while nonadherent patients were more likely to receive analog insulin delivered by vials in the first month of the postperiod. 
The Association Between Adherence to Insulin Therapy and Health Care Costs for

Adults with Type 2 Diabetes: Evidence from a U.S. Retrospective Claims Database

\section{TABLE 1$)$ Patient Characteristics}

\begin{tabular}{|c|c|c|c|c|c|c|}
\hline \multirow[b]{2}{*}{ Characteristic } & \multicolumn{3}{|c|}{ Basal Cohort } & \multicolumn{3}{|c|}{ Basal-Bolus Cohort } \\
\hline & $\begin{array}{l}\text { Adherent } \mathrm{t}^{\mathrm{a}} \\
(\mathrm{n}=5,502)\end{array}$ & $\begin{array}{l}\text { Nonadherent }{ }^{\mathrm{b}} \\
(\mathrm{n}=7,794)\end{array}$ & $P$ Value $^{\mathrm{c}}$ & $\begin{array}{l}\text { Adherent }^{\mathrm{a}} \\
(\mathrm{n}=2,006)\end{array}$ & $\begin{array}{c}\text { Nonadherent }{ }^{\mathrm{b}} \\
(\mathrm{n}=8,063)\end{array}$ & $P$ Value $^{c}$ \\
\hline \multicolumn{7}{|l|}{ Patient demographics } \\
\hline Age $($ mean \pm SD) & $56.1 \pm 9.0$ & $53.3 \pm 10.2$ & $<0.0001$ & $56.6 \pm 9.1$ & $54.4 \pm 10.1$ & $<0.0001$ \\
\hline Sex & & & 0.0136 & & & 0.0063 \\
\hline Female & $2,383 \quad(43.3)$ & $3,544 \quad(45.5)$ & & $851 \quad(42.4)$ & $3,694 \quad(45.8)$ & \\
\hline Male & $3,119 \quad(56.7)$ & $4,250 \quad(54.5)$ & & $1,155 \quad(57.6)$ & $4,369 \quad(54.2)$ & \\
\hline Region & & & $<0.0001$ & & & $<0.0001$ \\
\hline Northeast & $1,955 \quad(35.5)$ & $2,290 \quad(29.4)$ & & $742 \quad(37.0)$ & $2,454 \quad(30.4)$ & \\
\hline Midwest & $1,327 \quad(24.1)$ & $1,651 \quad(21.2)$ & & $492 \quad(24.5)$ & $1,700 \quad(21.1)$ & \\
\hline South & $1,953 \quad(35.5)$ & $3,363 \quad(43.1)$ & & $693 \quad(34.5)$ & $3,444 \quad(42.7)$ & \\
\hline West & $267 \quad(4.9)$ & $490 \quad(6.3)$ & & $79 \quad(3.9)$ & $465 \quad(5.8)$ & \\
\hline Insurance payment type & & & 0.0002 & & & 0.0008 \\
\hline Commercial & $2,757 \quad(50.1)$ & $3,759 \quad(48.2)$ & & $972(48.5)$ & $3,921 \quad(48.6)$ & \\
\hline Self & $2,430 \quad(44.2)$ & $3,458 \quad(44.4)$ & & $919 \quad(45.8)$ & $3,509 \quad(43.5)$ & \\
\hline Other & $227 \quad(4.1)$ & $452 \quad(5.8)$ & & $77 \quad(3.8)$ & $492 \quad(6.1)$ & \\
\hline Unknown & $88 \quad(1.6)$ & $125 \quad(1.6)$ & & $38 \quad(1.9)$ & $141 \quad(1.7)$ & \\
\hline \multicolumn{7}{|l|}{ Clinical and laboratory variables } \\
\hline Index BMI $($ mean \pm SD)d & $34.9 \pm 6.4$ & $33.8 \pm 6.9$ & $<0.0001$ & $35.7 \pm 6.6$ & $34.0 \pm 7.0$ & $<0.0001$ \\
\hline Number of Alc tests ordered in preperiod (mean \pm SD) & $1.9 \pm 1.41$ & $1.7 \pm 1.4$ & $<0.0001$ & $2.1 \pm 1.5$ & $1.9 \pm 1.5$ & $<0.0001$ \\
\hline \multicolumn{7}{|l|}{ Preperiod health and comorbidities } \\
\hline Charlson Comorbidity Index score (mean \pm SD) & $2.5 \pm 2.1$ & $2.5 \pm 2.2$ & 0.2916 & $2.9 \pm 2.4$ & $3.1 \pm 2.4$ & 0.0052 \\
\hline Diabetes Complications Severity Index score $($ mean \pm SD) & $1.3 \pm 1.8$ & $1.4 \pm 1.9$ & 0.0268 & $1.7 \pm 2.0$ & $1.9 \pm 2.1$ & 0.0003 \\
\hline Anxiety & $534 \quad(9.7)$ & $854(11.0)$ & 0.0201 & $163 \quad(8.1)$ & $1,042 \quad(12.9)$ & $<0.0001$ \\
\hline Depression & 709 (12.9) & $1,081 \quad(13.9)$ & 0.1018 & $272(13.6)$ & $1,291 \quad(16.0)$ & 0.0066 \\
\hline Hyperlipidemia & $3,596 \quad(65.4)$ & $4,590 \quad(58.9)$ & $<0.0001$ & $1,396 \quad(69.6)$ & $5,323(66.0)$ & 0.0024 \\
\hline Hypoglycemia & $760 \quad(13.8)$ & $1,230 \quad(15.8)$ & 0.0017 & $362(18.0)$ & $1,538 \quad(19.1)$ & 0.2919 \\
\hline \multicolumn{7}{|l|}{ Preperiod resource utilization } \\
\hline Cardiologist & $1,571 \quad(28.6)$ & $2,480 \quad(31.8)$ & 0.0001 & $656(32.7)$ & $2,938 \quad(36.4)$ & 0.0018 \\
\hline Endocrinologist & $885(16.1)$ & $1,211 \quad(15.5)$ & 0.3935 & $542(27.0)$ & $2,048 \quad(25.4)$ & 0.1377 \\
\hline Ophthalmologist & $1,079 \quad(19.6)$ & $1,262 \quad(16.2)$ & $<0.0001$ & $495 \quad(24.7)$ & $1,659 \quad(20.6)$ & 0.0001 \\
\hline Nephrologist & $314 \quad(5.7)$ & $485 \quad(6.2)$ & 0.2178 & $154 \quad(7.7)$ & $755 \quad(9.4)$ & 0.0183 \\
\hline Hospitalized & $1,114 \quad(20.2)$ & $2,259 \quad(29.0)$ & $<0.0001$ & $467 \quad(23.3)$ & $2,695 \quad(33.4)$ & $<0.0001$ \\
\hline ER visit & $403 \quad(7.3)$ & $854(11.0)$ & $<0.0001$ & $146 \quad(7.3)$ & $1,028 \quad(12.7)$ & $<0.0001$ \\
\hline Number of outpatient visits (mean \pm SD) & $17.9 \pm 20.7$ & $17.6 \pm 22.3$ & 0.5178 & $21.2 \pm 22.5$ & $22.2 \pm 27.5$ & 0.0851 \\
\hline \multicolumn{7}{|l|}{ Preperiod GLA use } \\
\hline Number of orals prescribed (mean \pm SD) & $1.5 \pm 1.2$ & $1.3 \pm 1.2$ & $<0.0001$ & $1.4 \pm 1.2$ & $1.2 \pm 1.1$ & $<0.0001$ \\
\hline Use of noninsulin injectable & $905 \quad(16.4)$ & $875 \quad(11.2)$ & $<0.0001$ & $354 \quad(17.6)$ & $1,010 \quad(12.5)$ & $<0.0001$ \\
\hline \multicolumn{7}{|l|}{ Initial GLA therapy } \\
\hline Pen/vial \& regular/analogue combinations & & & $<0.0001$ & & & $<0.0001$ \\
\hline Analog \& pen use in first month & $4,837 \quad(87.9)$ & $6,250 \quad(80.2)$ & & $1,708 \quad(85.1)$ & $6,430 \quad(79.7)$ & \\
\hline Analog \& vial use in first month & $579 \quad(10.5)$ & $1,344 \quad(17.2)$ & & $194 \quad(9.7)$ & $1,268 \quad(15.7)$ & \\
\hline Regular insulin use (pen or vial) in first month & $86 \quad(1.6)$ & $200 \quad(2.6)$ & & $104 \quad(5.2)$ & $365 \quad(4.5)$ & \\
\hline
\end{tabular}

Note: All descriptive statistics are represented as $n(\%)$, unless otherwise specified.

${ }^{a}$ Adherence is defined as PDC for the index drug (basal or basal-bolus) $\geq 80 \%$ in the postperiod.

${ }^{b}$ Nonadherence is defined as $P D C<80 \%$ in the postperiod.

cP values are based on results of t-tests for continuous variables and chi-square tests for categorical variables.

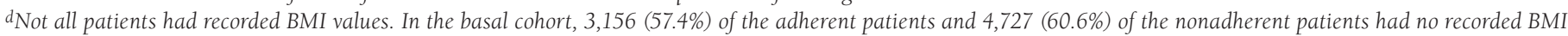
value on or before the index date. In the basal-bolus cohort, 1,078 (53.7\%) of the adherent patients and 4,803 (59.6\%) of the nonadherent patients had not recorded BMI values on or before the index date.

$B M I=$ body mass index; $E R=$ emergency room; $G L A=$ glucose-lowering agent; $P D C=$ proportion of days covered; $S D=$ standard deviation . 
The Association Between Adherence to Insulin Therapy and Health Care Costs for

Adults with Type 2 Diabetes: Evidence from a U.S. Retrospective Claims Database

TABLE 2 Unadjusted Preperiod and Postperiod Costs

\begin{tabular}{|c|c|c|c|c|c|c|c|}
\hline \multicolumn{4}{|c|}{ Basal Insulin Cohort } & \multicolumn{4}{|c|}{ Basal-Bolus Insulin Cohort } \\
\hline \multirow[b]{2}{*}{ Unadjusted Costs } & $\begin{array}{l}\text { Adherent } \\
(\mathrm{n}=5,502)\end{array}$ & $\begin{array}{c}\text { Nonadherent } \\
(\mathbf{n}=7,794)\end{array}$ & \multirow[b]{2}{*}{$P$ Value } & \multirow[b]{2}{*}{ Unadjusted Costs } & $\begin{array}{l}\text { Adherent } \\
(\mathrm{n}=2,006)\end{array}$ & $\begin{array}{c}\text { Nonadherent } \\
(\mathrm{n}=8,063)\end{array}$ & \multirow[b]{2}{*}{$P$ Value } \\
\hline & Mean \pm SD & Mean \pm SD & & & Mean \pm SD & Mean \pm SD & \\
\hline \multicolumn{4}{|l|}{ Preperiod costs } & \multicolumn{4}{|l|}{ Preperiod costs } \\
\hline \multicolumn{4}{|l|}{ All-cause costs } & \multicolumn{4}{|l|}{ All-cause costs } \\
\hline Total costs & $20,622 \pm 47,897$ & $27,070 \pm 74,177$ & $<0.0001$ & Total costs & $26,852 \pm 59,871$ & $36,861 \pm 89,885$ & $<0.0001$ \\
\hline Drug costs & $4,325 \pm 9,196$ & $3,488 \pm 9,286$ & $<0.0001$ & Drug costs & $6,654 \pm 9,521$ & $5,778 \pm 10,777$ & 0.0003 \\
\hline Outpatient costs & $8,280 \pm 23,418$ & $10,178 \pm 40,658$ & 0.0007 & Outpatient costs & $10,169 \pm 25,238$ & $13,907 \pm 49,473$ & $<0.0001$ \\
\hline Acute care costs & $8,017 \pm 33,407$ & $13,404 \pm 52,913$ & $<0.0001$ & Acute care costs & $10,030 \pm 46,627$ & $17,175 \pm 61,880$ & $<0.0001$ \\
\hline \multicolumn{4}{|c|}{ Diabetes-related costs } & \multicolumn{4}{|c|}{ Diabetes-related costs } \\
\hline Total costs & $5,566 \pm 12,883$ & $6,540 \pm 19,639$ & 0.0006 & Total costs & $8,260 \pm 13,176$ & $9,423 \pm 20,418$ & 0.0018 \\
\hline Drug costs & $1,647 \pm 2,481$ & $1,069 \pm 2,263$ & $<0.0001$ & Drug costs & $3,504 \pm 4,068$ & $2,504 \pm 3,265$ & $<0.0001$ \\
\hline Outpatient costs & $1,231 \pm 3,543$ & $1,417 \pm 10,097$ & 0.1341 & Outpatient costs & $1,638 \pm 4,502$ & $1,737 \pm 5,543$ & 0.3996 \\
\hline Acute care costs & $2,687 \pm 11,840$ & $4,055 \pm 16,338$ & $<0.0001$ & Acute care costs & $3,118 \pm 10,987$ & $5,182 \pm 18,987$ & $<0.0001$ \\
\hline \multicolumn{4}{|l|}{ Postperiod costs } & \multicolumn{4}{|l|}{ Postperiod costs } \\
\hline \multicolumn{4}{|l|}{ All-cause costs } & \multicolumn{4}{|l|}{ All-cause costs } \\
\hline Total costs & $29,322 \pm 45,246$ & $31,888 \pm 74,061$ & 0.0134 & Total costs & $36,229 \pm 50,069$ & $40,147 \pm 85,927$ & 0.0078 \\
\hline Drug costs & $11,578 \pm 12,347$ & $7,327 \pm 11,540$ & $<0.0001$ & Drug costs & $16,446 \pm 13,848$ & $10,380 \pm 13,440$ & $<0.0001$ \\
\hline Outpatient costs & $11,835 \pm 27,323$ & $14,176 \pm 44,657$ & 0.0002 & Outpatient costs & $13,792 \pm 37,500$ & $17,786 \pm 54,674$ & 0.0001 \\
\hline Acute care costs & $5,909 \pm 25,591$ & $10,385 \pm 44,981$ & $<0.0001$ & Acute care costs & $5,991 \pm 19,992$ & $11,981 \pm 50,705$ & $<0.0001$ \\
\hline \multicolumn{4}{|c|}{ Diabetes-related costs } & \multicolumn{4}{|c|}{ Diabetes-related costs } \\
\hline Total costs & $11,518 \pm 14,444$ & $9,186 \pm 21,683$ & $<0.0001$ & Total costs & $15,546 \pm 12,491$ & $12,424 \pm 24,907$ & $<0.0001$ \\
\hline Drug costs & $7,120 \pm 4,936$ & $3,474 \pm 3,422$ & $<0.0001$ & Drug costs & $11,021 \pm 6,479$ & $5,644 \pm 4,717$ & $<0.0001$ \\
\hline Outpatient costs & $2,125 \pm 6,234$ & $2,230 \pm 7,263$ & 0.3723 & Outpatient costs & $2,300 \pm 5,138$ & $2,631 \pm 9,423$ & 0.0334 \\
\hline Acute care costs & $2,273 \pm 11,285$ & $3,482 \pm 19,061$ & $<0.0001$ & Acute care costs & $2,226 \pm 8,723$ & $4,150 \pm 21,561$ & $<0.0001$ \\
\hline
\end{tabular}

Table 2 compares pre- and postperiod unadjusted all-cause and diabetes-related costs for patients in the BAS and BAS-BOL cohorts based on adherence status. Results reveal that in both cohorts, postperiod all-cause total costs were significantly lower for adherent patients, despite significantly higher diabetes-related total costs and all-cause and diabetes-related drug costs. Also in both cohorts, pre- and postperiod all-cause and diabetes-related acute care costs were significantly lower for adherent patients compared with nonadherent patients, as was all-cause outpatient costs. In both cohorts, adherent patients also had a greater proportion of postperiod overall drug costs attributable to diabetes medications than nonadherent patients (61.5\% vs. $47.4 \%$ in the BAS cohort; $67.0 \%$ vs. $54.4 \%$ in the BAS-BOL cohort).

Figure 2 and Figure 3 present the estimated differences in costs based on multivariable analyses for the BAS and BAS-BOL cohorts, respectively. In general, results are consistent with the descriptive statistics reported in Table 2. For example, in both cohorts, all-cause total costs were significantly lower for adherent patients compared with nonadherent patients $(\$ 30,127$ vs. $\$ 37,049,95 \% \mathrm{CI}=-\$ 8,460$ to $-\$ 5,384$ for BAS; $\$ 36,603$ vs. $\$ 44,702,95 \% \mathrm{CI}=-\$ 9,219$ to $-6,980$ for BAS-BOL). Similarly, all-cause acute care costs were significantly lower for adherent patients in both cohorts $(\$ 6,181$ vs. $\$ 10,054,95 \% C I=-\$ 4,009$ to $-\$, 3,737$ for BAS; $\$ 6,024$ vs. $\$ 11,835,95 \% C I=-\$ 5,910$ to $-\$ 5,711$ for BAS-BOL), as was diabetes-related acute care costs $(\$ 2,420$ vs. $\$ 3,446,95 \% \mathrm{CI}=-\$ 1,078$ to $-\$ 976$ for BAS; $\$ 2,364$ vs. $\$ 4,030,95 \% \mathrm{CI}=-\$ 1,710$ to $-\$ 1,622$ for BAS-BOL), allcause outpatient costs ( $\$ 13,839$ vs. $\$ 18,988,95 \% \mathrm{CI}=-\$ 5,793$ to $-\$ 4,503$ for BAS; $\$ 14,845$ vs. $\$ 24,263,95 \% C I=-\$ 10,052$ to $-\$ 8,784$ for BAS-BOL), and diabetes-related outpatient costs $(\$ 2,183$ vs. $\$ 2,360,95 \% \mathrm{CI}=-\$ 194$ to $-\$ 161$ for BAS; $\$ 2,364$ vs. $\$ 2,753,95 \% \mathrm{CI}=-\$ 410$ to $-\$ 368$ for BAS-BOL).

In contrast, diabetes-related total costs were significantly higher for adherent patients compared with nonadherent patients in both cohorts ( $\$ 11,516$ vs. $\$ 9,247,95 \% \mathrm{CI}=\$ 2,200$ $\$ 2,338$ for BAS; $\$ 15,562$ vs. $\$ 12,396,95 \% \mathrm{CI}=\$ 3,094-\$ 3,237$ for BAS-BOL). All-cause drug costs were also significantly higher for adherent patients in both cohorts $(\$ 11,606$ vs. $\$ 7,480,95 \% \mathrm{CI}=\$ 4,077-\$ 4,175$ for BAS; $\$ 16,470$ vs. $\$ 10,488$, $95 \% \mathrm{CI}=\$ 5,942-\$ 6,023$ for BAS-BOL), as was diabetes-related drug costs ( $\$ 7,132$ vs. $\$ 3,480,95 \% \mathrm{CI}=\$ 3,636-\$ 3,668$ for BAS; $\$ 11,029$ vs. $\$ 5,666,95 \% \mathrm{CI}=\$ 5,336-\$ 5,390$ for BAS-BOL). 


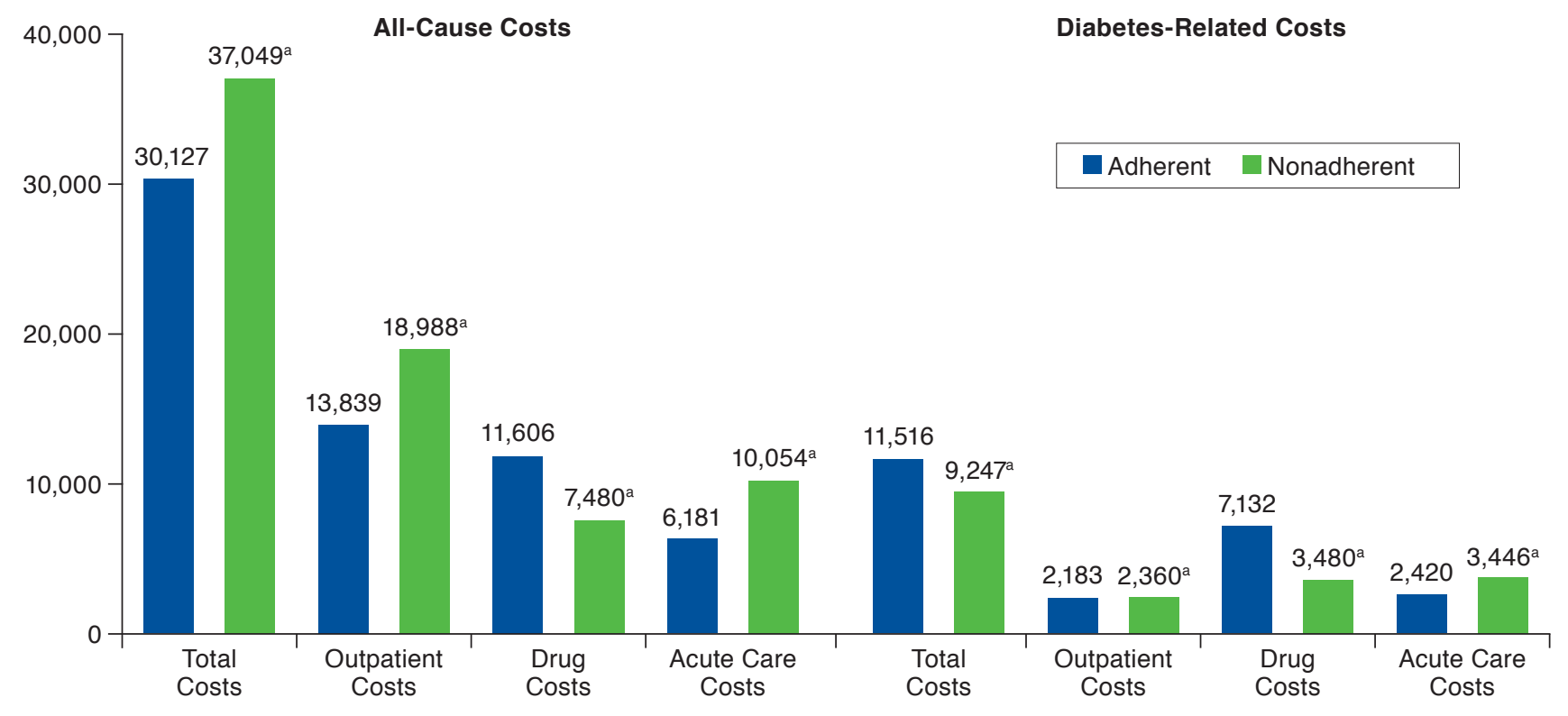

aDifferences in costs are statistically significant based on $95 \%$ confidence intervals in means. Results are from multivariable analyses that control for patient characteristics, preperiod general health and comorbidities, preperiod utilization, and preperiod medication use.

\section{Discussion}

In this study of patients who initiated either BAS or BAS-BOL insulin regimens, unadjusted descriptive statistics and multivariable analyses revealed that adherence was associated with significantly lower all-cause total health care costs during the same year. As such, study findings are consistent with previous research, which has found that patients who are adherent to GLAs generally have better health outcomes, including less hospitalization and ER use, complications, and short-term disability days..$^{25-29}$ In addition, these study findings are in concert with research that has reported an association between adherence to BAS therapy and better patient outcomes. ${ }^{3}$

A recent meta-analysis of the association between medication adherence and outcomes among patients with T2D treated with GLAs reveal that the findings of this study regarding all-cause costs are largely consistent with previous research. ${ }^{7}$ Specifically, the majority of studies have found that adherence was associated with significantly lower all-cause total costs, $, 8,30-33$ despite the significant increase in all-cause medication costs associated with improved adherence. ${ }^{31,34}$ Furthermore, previous research has also found that improved adherence is associated with significantly lower inpatient and/or ER costs. ${ }^{28,32}$

Previous research that has examined the relationship between medication adherence and total and diabetes-related costs among patients with T2D who are using insulin have found more mixed results. For example, Chandran et al. (2015) found that improved adherence to insulin pen therapy was associated with significant increases in post-index diabetesrelated total costs, ${ }^{8}$ while Perez-Nieves et al. (2018) found that greater adherence with basal insulin was associated with significant reductions in total and diabetes-related total costs, although there was no difference in diabetes-related total costs between adherent and nonadherent patients when adherence was proxied by medication possession ratio rather than PDC. ${ }^{3}$

For the BAS and BAS-BOL cohorts, improved adherence was associated with significantly lower all-cause and diabetesrelated acute care costs. These reductions in acute care costs represent potentially large savings for payers, since previous research has found that $32.7 \%$ of all U.S. direct diabetes health care spending in 2017 consisted of hospitalization and ER costs. ${ }^{35}$ Furthermore, reductions in acute care costs have been shown to be associated with reduced hospitalization and ER resources. ${ }^{3}$ Given that fewer hospitalizations may be associated with improved long-term outcomes and increased healthrelated quality of life, ${ }^{36}$ the reductions in acute care costs may represent humanistic benefits to patients.

Few previous studies have examined the total health care costs of T2D patients on insulin therapy, let alone compared the costs of individuals using BAS with those using BAS-BOL. However, the adjusted total, mean, annual, per patient costs of the BAS cohort in this study $(\$ 30,127$ adherent; $\$ 37,049$ 


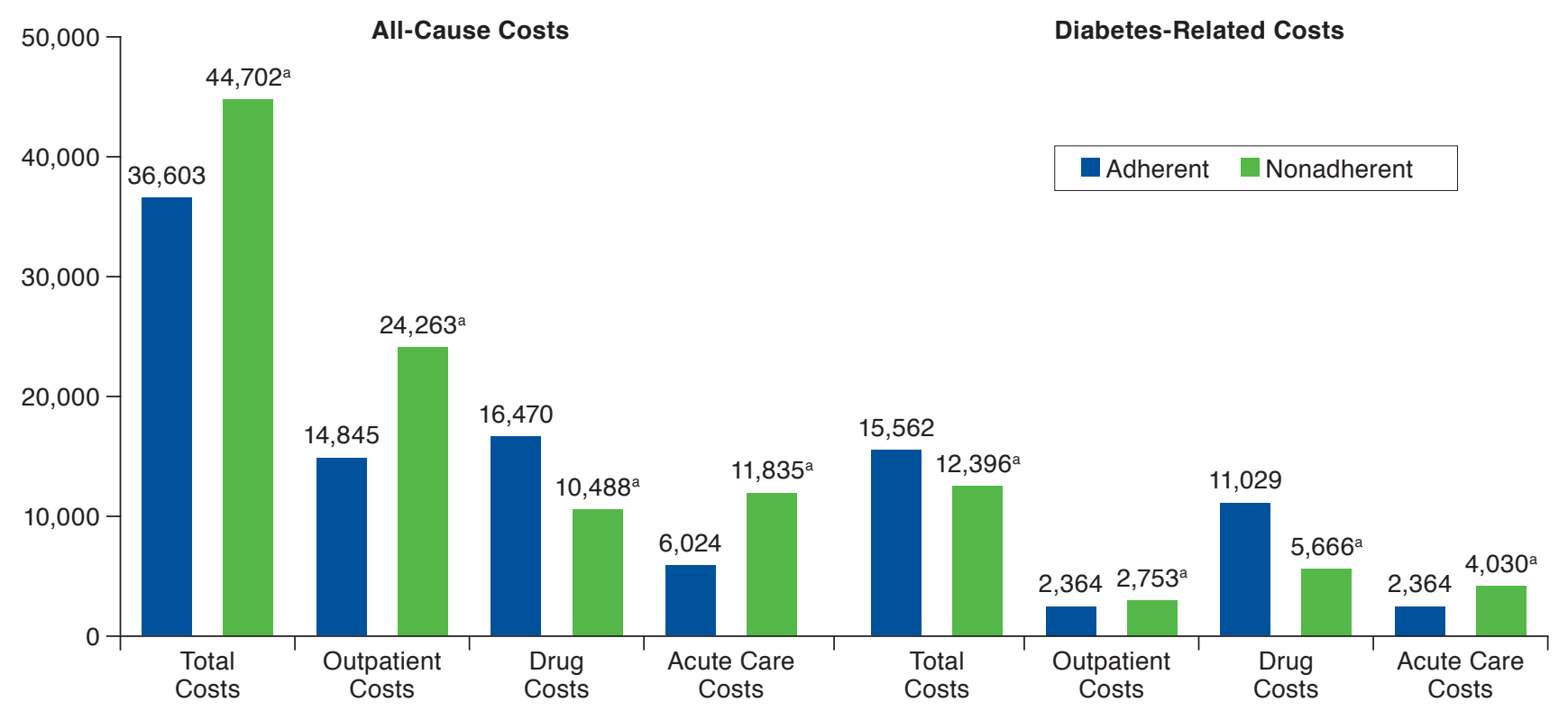

aDifferences in costs are statistically significant based on $95 \%$ confidence intervals in means. Results are from multivariable analyses that control for patient characteristics, preperiod general health and comorbidities, preperiod utilization, and preperiod medication use.

nonadherent) are generally consistent with, if slightly higher than, the 3-year health care costs of patients on BAS therapy reported in the Perez-Nieves et al. study $(\$ 73,687$ adherent; $\$ 78,778$ nonadherent; $P<0.0001) .{ }^{3}$ Our results are also broadly consistent with those of the Chandran et al. study of insulin pen users that used data from 2006-2010 and reported mean, annual, per patient health care costs in 2011 dollars of $\$ 26,310$ for the least adherent and $\$ 23,839$ for the most adherent patients $(P=0.007){ }^{8}$

\section{Limitations}

The results of this study must be interpreted within the context of some limitations. First, the analyses used insurance claims information on prescription fills as a proxy for adherence. This proxy does not allow for any measure of whether prescriptions were used once filled or used in a manner consistent with the physician's intention and does not capture any insulin use that was not submitted for insurance reimbursement.

Second, this measure identified all discontinuations in therapy as a lack of adherence, since the reason for such discontinuations was not known. As a result, patients who switched or discontinued therapy because of adverse events or changes in physician prescribing orders were categorized as nonadherent.

Third, this study relied on patients who were commercially insured for at least 2 years, and such patients may not be generalizable to the entire population of adults with T2D. Fourth, the analyses were unable to control for factors such as race, socioeconomic status, or duration of diabetes. These factors may be associated with patient outcomes but were not captured in the claims data. The analysis methodology was meant to be descriptive and was not meant to provide an estimate of the causal effect of adherence on costs.

Fifth, by defining the cohorts (adherence levels) during the same period as the outcome (cost), we did not fully establish the temporal order for causal inference. It is thus possible that costs (or drivers of cost) could have influenced other variables that affected later adherence and thus the outcome influences cohort assignment.

Finally, the analysis focused exclusively on statistical significance and did not consider whether such differences were clinically significant.

\section{Conclusions}

The results from this study illustrate that patients who are adherent to either BAS or BAS-BOL therapies have significantly lower all-cause total health care costs compared with nonadherent patients, despite having higher all-cause and diabetesrelated drug costs and higher diabetes-related total costs. In particular, adherent patients had substantially lower all-cause and diabetes-related acute care costs, suggesting fewer or less severe episodes of hospitalization or ER visits. These findings suggest that adherence to either a BAS or BAS-BOL regimen 
may be associated with lower overall costs for payers during the first year of initiation of these regimens.

\section{Authors}

ELIZABETH L. EBY, MPH; SANJAY BAJPAI, PhD; DOUGLAS E. FARIES, PhD; and VIRGINIA S. HAYNES, PhD, Eli Lilly and Company, Indianapolis, Indiana. MAUREEN J. LAGE, PhD, HealthMetrics Outcomes Research, Bonita Springs, Florida.

AUTHOR CORRESPONDENCE: Maureen J. Lage, PhD, HealthMetrics Outcomes Research, 27576 River Reach Dr., Bonita Springs, FL 34134. Tel.: 860.625.5804; Email: lagemj@hlthmetrics.com.

\section{DISCLOSURES}

Eli Lilly and Company funded this study and was responsible for study design and execution. Bajpai, Eby, Faries, and Haynes are employees and own stock in Eli Lilly and Company. Lage received compensation from Eli Lilly and Company for her work on this research project.

\section{ACKNOWLEDGMENTS}

The authors thank Patricia Platt for her assistance in the writing of the manuscript.

\section{REFERENCES}

1. Home P, Riddle M, Cefalu WT, et al. Insulin therapy in people with type 2 diabetes: opportunities and challenges? Diabetes Care. 2014;37(6):1499-508.

2. Cani CG, Lopes L da SG, Queiroz M, Nery M. Improvement in medication adherence and self-management of diabetes with a clinical pharmacy program: a randomized controlled trial in patients with type 2 diabetes undergoing insulin therapy at a teaching hospital. Clinics (Sao Paulo). 2015;70(2):102-06

3. Perez-Nieves M, Boye KS, Kiljanski J, Cao D, Lage MJ. Adherence to basal insulin therapy among people with type 2 diabetes: a retrospective cohort study of costs and patient outcomes. Diabetes Ther. 2018;9(3):1099-111.

4. Bundrick Harrison L, Lingvay I. Appointment and medication nonadherence is associated with increased mortality in insulin-treated type 2 diabetes. Evid Based Med. 2013;18(3):112-13.

5. Peyrot M, Barnett AH, Meneghini LF, Schumm-Draeger P-M. Insulin adherence behaviours and barriers in the multinational Global Attitudes of Patients and Physicians in Insulin Therapy study. Diabet Med. 2012;29(5):682-89.

6. Munshi MN, Slyne C, Greenberg JM, et al. Nonadherence to insulin therapy detected by bluetooth-enabled pen cap is associated with poor glycemic control. Diabetes Care. 2019;42(6):1129-31.

7. Kennedy-Martin T, Boye KS, Peng X. Cost of medication adherence and persistence in type 2 diabetes mellitus: a literature review. Patient Prefer Adherence. 2017;11:1103-17.

8. Chandran A, Bonafede MK, Nigam S, Saltiel-Berzin R, Hirsch LJ, Lahue BJ. Adherence to insulin pen therapy is associated with reduction in healthcare costs among patients with type 2 diabetes mellitus. Am Health Drug Benefits. 2015;8(3):148-58.
9. Cobden D, Lee WC, Balu S, Joshi AV, Pashos CL. Health outcomes and economic impact of therapy conversion to a biphasic insulin analog pen among privately insured patients with type 2 diabetes mellitus. Pharmacotherapy. 2007;27(7):948-62.

10. Ayyagari R, Wei W, Cheng D, Pan C, Signorovitch J, Wu EQ. Effect of adherence and insulin delivery system on clinical and economic outcomes among patients with type 2 diabetes initiating insulin treatment. Value Health. 2015;18(2):198-205.

11. Eby EL, Zagar AJ, Wang P, et al. Healthcare costs and adherence associated with human regular U-500 versus high-dose U-100 insulin in patients with diabetes. Endocr Pract. 2014;20(7):663-70.

12. American Diabetes Association. 8. Pharmacologic approaches to glycemic treatment. Diabetes Care. 2017;40(Suppl 1):S64-74.

13. Klompas M, Eggleston E, McVetta J, Lazarus R, Li L, Platt R. Automated detection and classification of type 1 versus type 2 diabetes using electronic health record data. Diabetes Care. 2013;36(4):914-21.

14. Pharmacy Quality Alliance. PQA measure overview. 2019. Available at: https://www.pqaalliance.org/assets/Measures/2019_PQA_Measure_ Overview.pdf. Accessed July 7, 2020.

15. Centers for Medicare \& Medicaid Services. 2018 Medicare-Medicaid plan performance data technical notes. April 2018. Available at: https://www.cms. gov/Medicare-Medicaid-Coordination/Medicare-and-MedicaidCoordination/Medicare-Medicaid-Coordination-Office/Financial AlignmentInitiative/Downloads/MMPPerformanceDataTechNotes CY2018_04252018.pdf. Accessed July 7, 2020.

16. Tang KL, Quan H, Rabi DM. Measuring medication adherence in patients with incident hypertension: a retrospective cohort study. BMC Health Serv Res. 2017;17(1):135.

17. Buysman E, Conner C, Aagren M, Bouchard J, Liu F. Adherence and persistence to a regimen of basal insulin in a pre-filled pen compared to vial/syringe in insulin-naive patients with type 2 diabetes. Curr Med Res Opin. 2011;27(9):1709-17.

18. Diabetes.co.uk. Insulin dosage. January 2019. Available at: https://www. diabetes.co.uk/insulin/insulin-dosage.html. Accessed July 7, 2020.

19. Krass I, Schieback P, Dhippayom T. Adherence to diabetes medication: a systematic review. Diabet Med. 2015;32(6):725-37.

20. U.S. Bureau of Labor Statistics. Consumer Price Index for all urban consumers: medical care services in the U.S. city average, series ID CUUR0000SAM2, CUUS0000SAM2. Available at: https://www.bls.gov/ data/. Accessed July 7, 2020.

21. Malehi AS, Pourmotahari F, Angali KA. Statistical models for the analysis of skewed healthcare cost data: a simulation study. Health Econ Rev. 2015;5:11.

22. Mihaylova B, Briggs A, O'Hagan A, Thompson SG. Review of statistical methods for analysing healthcare resources and costs. Health Econ. 2011;20(8):897-916

23. Quan H, Sundararajan V, Halfon P, et al. Coding algorithms for defining comorbidities in ICD-9-CM and ICD-10 administrative data. Med Care. 2005;43(11):1130-39.

24. Chang H-Y, Weiner JP, Richards TM, Bleich SN, Segal JB. Validating the adapted Diabetes Complications Severity Index in claims data. Am J Manag Care. 2012;18(11):721-26.

25. Gibson TB, Song X, Alemayehu B, et al. Cost sharing, adherence, and health outcomes in patients with diabetes. Am J Manag Care. 2010;16(8):589-600.

26. Jha AK, Aubert RE, Yao J, Teagarden JR, Epstein RS. Greater adherence to diabetes drugs is linked to less hospital use and could save nearly $\$ 5$ billion annually. Health Aff (Millwood). 2012;31(8):1836-46.

27. Juarez DT, Tan C, Davis J, Mau M. Factors affecting sustained medication adherence and its impact on health care utilization in patients with diabetes. J Pharm Health Serv Res. 2013;4(2):89-94. 
28. Encinosa WE, Bernard D, Dor A. Does prescription drug adherence reduce hospitalizations and costs? The case of diabetes. Adv Health Econ Health Serv Res. 2010;22:151-73.

29. Cheng S-H, Chen C-C, Tseng C-H. Does medication adherence lead to lower healthcare expenses for patients with diabetes? Am J Manag Care. 2013;19(8):662-70

30. Gentil L, Vasiliadis H-M, Préville M, Berbiche D. Adherence to oral antihyperglycemic agents among older adults with mental disorders and its effect on health care costs, Quebec, Canada, 2005-2008. Prev Chronic Dis. 2015; 12:E230.

31. Hansen RA, Farley JF, Droege M, Maciejewski ML. A retrospective cohort study of economic outcomes and adherence to monotherapy with metformin, pioglitazone, or a sulfonylurea among patients with type 2 diabetes mellitus in the United States from 2003 to 2005. Clin Ther. 2010;32(7):1308-19.

32. Hong JS, Kang HC. Relationship between oral antihyperglycemic medication adherence and hospitalization, mortality, and healthcare costs in adult ambulatory care patients with type 2 diabetes in South Korea. Med Care. 2011;49(4):378-84.
33. Shenolikar RA, Balkrishnan R, Camacho FT, Whitmire JT, Anderson RT. Comparison of medication adherence and associated health care costs after introduction of pioglitazone treatment in African Americans versus all other races in patients with type 2 diabetes mellitus: a retrospective data analysis. Clin Ther. 2006;28(8):1199-207.

34. Egede LE, Gebregziabher M, Dismuke CE, et al. Medication nonadherence in diabetes: longitudinal effects on costs and potential cost savings from improvement. Diabetes Care. 2012;35(12):2533-39.

35. American Diabetes Association. Economic costs of diabetes in the U.S. in 2017. Diabetes Care. 2018;41:917-28.

36. Courtney M, Edwards H, Chang A, Parker A, Finlayson K, Hamilton K. Fewer emergency readmissions and better quality of life for older adults at risk of hospital readmission: a randomized controlled trial to determine the effectiveness of a 24-week exercise and telephone follow-up program. J Am Geriatr Soc. 2009;57(3):395-402. 